than "painful." This fact may account for the virtual absence of emotional behavior on the S's part. Apparently, the nonemotional characteristic of avoidance behavior in the present situation is not unique. D'Amato (1969, p. 108) has recently recounted some similar observations and has discussed the problem of avoidance without "fear." Summarily, these results are encouraging in regard to employing the air-blast technique to study human avoidance behavior. Most Ss are able to acquire a simple $\mathrm{Ra}$ with in 40 trials. Moreover, use of instructions that provide some degree of information concerning the situation seems desirable. However, the procedure of permitting escape as well as avoidance responses does not appear to be critical in establishing the behavior.

\section{REFERENCES}

BAIR, D. Effects of air blast intensity on the acquisition and extinction of a human avoidance response. Unpublished MA thesis, University of South Dakota, 1969.

BANDURA, A. Principles of behavior modification. New York: Holt, Rinehart, \&
Winston, 1969.

BEFCROFT, R. S. Imotional conditioning. Psychonomic Monograph Supplements. 1967. 2, 45-72.

BOLLES. R. C. Species-specific defense reactions and avoidance learning. Psychological Review, $1970,77,32-48$.

D'AMATO, M. R. Instrumental conditioning with negative reinforcement. In M. H. Marx (Ld.), Learning: Processes. London: Collier-Macmillan, 1969. Pp. 35-118.

EYSENCK, H. J., \& RACHMAN, S. The causes and cures of neurosis. San Diego, Calif: Knapp, 1965.

HERRNSTEIN, R. J. Method and theory in the study of avoidance. Psychological Review, 1969, 76, 49-69.

STONE, G. C. Nondiscriminated avoidance behavior in human subjects. Science, 1961, $133,641-642$

TURNER, L. H., \& SOLOMON, R. L. Human traumatic avoidance learning: Theory and experiments on the operant-respondent distinction and failures to learn. Psychological Monographs, 1962, 76(40, Whole No. 559).

ULLMAN, L. P., \& KRASNER, L. $A$ psychological approach to normal behavior. Englewood-Cliffs, N.J : Prentice-Hall, 1969.

WOLPE, J., \& LAZARUS, A. A. Behavior therapy techniques: $A$ guide to the treatment of neuroses. New York: Pergamon Press, 1966.

\title{
Retrieval of words from subordinate and superordinate categories in semantic hierarchies*
}

\author{
ELIZABETH F. LOFTUS, $\uparrow$ Stanford University, Stanford, Calif. 94305 \\ JONATHAN L. FREEDMAN, Columbia University, New York, N.Y. 10037 \\ and \\ GEOFFREY R. LOFTUS, Stanford University, Stanford, Calif. 94305
}

Retrieval from long-term memory was investigated in an experiment in which $\mathrm{S}$ was shown a category name and asked to respond with a word belonging to the category (e.g., animal-horse, bird-robin). The reaction time (RT) taken to re trieve a member of a given category was not significantly different from the time taken to retrieve a member of a superset of that category. For example, Ss could produce an instance of the category "bird" as quickly as they could produce an instance of the category "animal." The time taken to retrieve a category member was found to be strongly related to the Thorndike-Lorge frequency of the most frequent category member. The data support the notion of a semantic organization in which the category name can be located directly, rather than being accessible only via a search along a hierarchical path.

Every word that is part of our semantic memory belongs to an extensive network of associations and can be categorized in various ways. Current theories treat long-term memory as though it consisted of a large number of interconnected and cross-referenced associative and category

\footnotetext{
*The authors wish to thank Lauren Dyer who patiently collected the data. The study was supported in part by a National Science Foundation grant to J. Freedman and was conducted while E. Loftus was on a Public Health Service Fellowship.

$\dagger$ Now at the New School for Social Rescarch.
}

networks (e.g., Pollio, 1968). Although it is not yet possible to provide precise details about these category networks, it may be fruitful to make general distinctions among possible types of networks and to determine what implications they have for retrieval.

One plausible model views memory as though it were organized as a single predefined hierarchy (Green, Wolf, Chomsky, \& Laughery, 1963; Lindsay, 1963). A search process is assumed to begin at the top of the hierarchy and to follow pathways downward through the network. Green et al's simulation program demonstrated that this kind of memory can be interrogated with natural language questions; Lindsay's program showed that such a memory structure can provide certain inference-making properties. If we accept this view of semantic organization, what are the implications for retrieval? A portion of a hypothetical memory structure might consist of "living thing," with "animal" and "vegetable" as subsets of it, the superset "bird" and "snake" as subsets of "animal," and "canary" and "robin" as instances of the subset "bird." If the category name cannot be located directly, but must be found by beginning at the top of the semantic hierarchy and searching downward through the hierarchy, the time required to retrieve an instance of any category should reflect the number of supersets through which $\mathbf{S}$ must move before finding the appropriate category. Thus, we would expect the time taken to retrieve an instance of the category "bird" to be greater than the time to retrieve an animal, because $\mathrm{S}$ must move through at least one extra superset to locate the category "bird." Note that we have operationally described the hierarchy by assuming that, for a superordinatesubordinate pair of categories such as animal-bird, the superordinate (which includes everything that belongs in the subordinate category) will be higher in the hierarchy. For any superordinatesubordinate pair, then, retrieving an instance of the superordinate category should, according to this model, take less time.

Another possible type of memory structure (cf. Quillian, 1967, 1968, and Collins \& Quillian, 1969) assumes that there is no predetermined hierarchy of supersets and subsets or of categories and subcategories. When a search process begins with a particular word, that word is the patriarch of its own separate hierarchy. For example, according to the model, the word "bird" heads its own hierarchy when a search process begins with "bird," while "animal" heads its own hierarchy when the search is for an animal. As such, the word is directly accessible by some central processor, instead of being accessible only via a search along a hierarchical path. Thus, there is no reason to expect any difference between the RT taken to retrieve an instance of the category "bird" and the RT taken to retrieve an instance of the category "animal." In general, it is not necessary for $S$ to search along a hierarchical path to retrieve a category name; rather, he can locate it directly and then produce the strongest correct association.

The present experiment was designed to 
Tabie 1

Vean Reaction Time Taken to Name an Instance of a Category for 20 Sets of Vested Categories Superordinate Category Subordinate Catcoor!

\begin{tabular}{llll} 
Cits & 1.19 & L.S. City & 1.34 \\
Nusical lnstrument & 1.44 & Stringed lnstrunent & 1.50 \\
lirt Name & 1.32 & Boy Name & 1.27 \\
Building & 1.87 & Place of Worship & 1.32 \\
Anima1. & 1.38 & Bird & 1.53 \\
Beverage & 1.39 & Alcoholic Beverage & 1.74 \\
Plant & 1.81 & Tree & 1.48 \\
Government Position & 1.59 & President & 1.37 \\
Vehicle & 1.09 & Car & 1.69 \\
Activity & 1.45 & Sport & 1.17 \\
Profession & 1.37 & Type of Clergy & 1.87 \\
Word & 1.71 & Noun & 2.18 \\
Clothing & 1.70 & lootwear & 1.14 \\
Living Thing & 1.55 & Dog & 1.61 \\
Food & 1.92 & Vegetable & 1.55 \\
Stone & 2.01 & Gem & 1.54 \\
Title & 1.99 & Military Title & 1.51 \\
Adjective & 1.69 & Color & .99 \\
Country & 1.22 & European Country & 1.41 \\
Element & 2.33 & Metal & 1.39 \\
\hline
\end{tabular}

compare these two models by determining whether the RT required to name an instance of a category is dependent upon the position of the category in a predefined semantic hierarchy. In designing the experiment, a central problem was to ensure that categories used could be classified accurately according to their relative position in the hierarchy. This was accomplished by using pairs of nested categories in which the superordinate category included, by definition, everything that belonged in the subordinate category. For example, the category "beverages" contains all alcoholic beverages, "musical instruments" contains all stringed instruments, and "animals" contains all birds. In this experiment $S$ was presented with both a superset name (e.g., beverage), and required to give a member of that category, and a subset name (e.g., alcoholic beverage), and required to give a member of it. This allows a direct comparison of the time taken to produce members of supersets and subsets.

\section{METHOD}

The Ss were 32 students from the introductory psychology course at Stanford University.

Twenty pairs of nested category names were constructed. For each pair of categories, the superordinate category included everything that belonged in the subordinate category. The nested categories used are presented in Table 1. The category names were printed on $5 \times 8$ in. cards, with one category per card. In addition, 20 other unnested categories were used. Each $S$ received a random permutation of the 60 categories, with one category per trial.

A typical trial follows: A card with the category name printed in large type was placed in a darkened enclosure behind a half-silvered mirror. The E said "ready" and pressed a button which illuminated the card and simultaneously started an electric timer. The S's verbal response activated a voice key which stopped the clock and terminated the trial. The $S$ was told to respond with the first word that he could think of belonging to the category. The Ss were urged to avoid errors but encouraged to respond as quickly as possible. A warmup period of 18 trials preceded the experimental trials. The total experiment took about $30 \mathrm{~min}$.

\section{RESULTS AND DISCUSSION}

Only correct responses (95\%) to the 20 pairs of nested categories are included in the following analyses. Mean RTs were computed for each of these 40 categories and are presented in Table 1 . The major focus of the study was on the effect of the hierarchical position of a category on the time taken to produce a member of that category. The geometric mean time to produce a member of a superordinate category was $1.60 \mathrm{sec}$ and to produce a member of a subordinate category was $1.49 \mathrm{sec}$. This difference does not approach significance $[t(19)=.12]$.

This result is inconsistent with a model that describes memory as consisting of a predefined hierarchy. Such a model, in which a search process is assumed to begin at the top of the hierarchy, would predict longer RT for a subset category than for a superordinate category, since the subset is hierarchy. The present result actually indicates a slight difference in the opposite direction and is thus inconsistent with this view. These data are, however, consistent with a model in which each category heads its own hierarchy and some central processor can directly locate each category name.

A second result concerns the effect of word frequency on reaction times. Each of located closer to the bottom of the the 40 categories was ranked according to the frequency in English. according to Thorndike-Lorge (1944), of the most frequent member of the category. There was a strong correlation between category frequency and reaction time $(r=.62$, $p<.001)$. As long ago as 1901. Marbe's law (Thumb \& Narbe. 1901: cited in Woodworth \& Schlosberg. 1954) stated that more frequent responses in a free-association test were given more quickly, and this has been confirmed by other studies (e.g., Wreschner. 1907; Cason $\&$ Cason, 1925). Since the frequency with which a response is given in various kinds of restricted association tests is highly correlated with its frequency in the language (Duncan, 1966), the present finding would seem to be one more demonstration that the higher the frequency of a response, the more quickly it is given. This suggests that, in his search for an appropriate response, once $S$ locates the correct category name in his memory store, he tends to produce the highest frequency word in that category.

\section{REFERENCES}

CASON, H. \& CASON, E. B., Association tendencies and learning ability. Journal of Experimental Psychology. 1925, 8, 167-189.

COLLINS, A. M.. \& QUILLIAN. M. R. Retrieval time from semantic memory. Journal of Verbal Learning \& Verbal Behavior. 1969, 8, $240-247$.

DLINCAN, C. P. Effect of word frequency on thinking of a word. Journal of Verbal Learning \& Verbal Behavior, 1966, 5, 434-440.

GREEN, B. R., JR., WOLF, A. K., CHOMSKY, C., \& LAUGHERY, K. Baseball: An automatic question answerer. In E. A. Feigenbaum and J. Feldman (Eds.), Computers and thought. New York: McGraw-Hill, 1963. Pp. 207-216.

LINDSAY, R. K. Inferential memory as the basis of $m$ achines which understand natural language. In E. A. Feigenbaum and J. Feldman (Eds.), Computers and thought. New York: McGraw-Hill, 1963. Pp. 217-233.

POLLIO, H. K. Assoclattve structure and verbal behavior. In T. R. Dixon and D. L. Horton (Eds.), Verbal behavior and general behavior theory. Englewood-Cliffs, N.J: Prentice-Hall. 1968. Pp. 37-66.

QUILLIAN, M. R. Word concepts: $A$ theory and simulation of some basic semantic capabilities. Behavioral Science, 1967, 12,410-430.

QUILLIAN, M. R. Semantic memory. In M. Minsky (Ed.), Sementic information processing. Cambridge, Mass: M.I.T. Press, 1968. Pp. 216-270.

THORNDIKE, E. L., \& LORGE, I. The teacher's word book of 30,000 words. New York: Bureau of Publications, Teachers College, Columbia University, 1944.

THUMB, A., \& MARBE, K. Experimentelle Untersuchungen uber die psychologischen Grundlagen der sprachlichen Analogiebildung. Leipzig: Engelmann, 1901.

WOODWORTH, R. S., \& SCHLOSBERG, H. Experimetnal psychology. New York: Holt. 1954.

WRESCHNER. A. Die Reproduktion und Assoziation von Vorstellungen. Zeitschrift fur Psychologische Erganzungsband, 1907, No. 3. 